\section{Perceptions of Environmental Health and Willingness to Compost Fresh Cut Floral Waste by Retail Flower Shop Owners}

\author{
Coleman L. Etheredge ${ }^{1}$ and Tina M. Waliczek ${ }^{2}$
}

ADDITIONAL INDEX WORDS. environmental attitudes, environmentalism, floral design, floriculture, florist

SuMMARY. In the United States there has been a push to convert industries to a more environmentally sustainable business attitude in recent years. Environmentally sustainable practices are not only good for the environment, but there is increasing evidence these practices lead to an increase in customer loyalty. The trend of selfregulation, willingly imposing more stringent environmental policies than required by the government, is progressing toward a time where environmentally friendly practices will be a competitive necessity for businesses to survive. The main purpose of this research was to investigate the perceptions of environmental health of retail flower shop owners and their willingness to recycle fresh cut floral waste produced at retail flower shops for use as compost and to determine if there is a statistical correlation between environmental awareness and willingness to compost fresh cut flower waste. A mailing list of retail florists from across the United States was compiled. A total of 1974 florists from all 50 states were sent a standardized e-mail explaining the purpose of the study. Embedded in the e-mail was a hyperlink that redirected willing respondents to the survey. Each person on the mailing list was emailed one time. Of the $\mathbf{3 0 0}$ retail florists who took part in the survey, a majority, 190 (63.33\%), were ranked as having "high concern" for environmental health. A majority of florists $247(82.33 \%)$ "agreed" or "strongly agreed" to collaborate with Master Gardener programs and other organizations if it meant they could recycle their floral waste through composting. Through the creation of industry- and statesponsored certifications, florists could brand and promote their business as more environmentally conscious by composting their floral waste. This could possibly, in turn, stimulate sales and increase profit margins while having the added benefit of reducing the amount of waste entering landfills.

I $\mathrm{n}$ recent years, industries have begun to restructure their business model to one that is more environmentally sustainable (Ouvrard et al., 2020). Due to rising concerns about health risks and environmental degradation related to the overuse of pesticides, there are increases in "organic," "sustainable," and "fair trade" branded items being sold in the United States and around the world (Lernoud and Willer, 2017; Toumi et al., 2016). These brands are related

Received for publication 1 Sept. 2020. Accepted for publication 12 Oct. 2020

Published online 9 November 2020.

${ }^{1}$ Department of Plant and Soil Sciences, Mississippi State University, Starkville, MS 39759

${ }^{2}$ Department of Agricultural Sciences, Texas State University, San Marcos, TX 78666

C.L.E. is an Assistant Professor.

T.M.W. is a Professor.

C.L.E. is the corresponding author. E-mail: cle248@ msstate.edu.

This is an open access article distributed under the CC BY-NC-ND license (https://creativecommons.org/ licenses/by-nc-nd/4.0/).

https://doi.org/10.21273/HORTTECH04724-20 to certifications that help to ensure growing conditions meet or exceed legal government mandates and industry norms as they relate to environmental sustainability (Lernoud and Willer, 2017; Raynold, 2012).

Environmentally healthy practices are not only good for the environment, but there is increasing evidence that these practices lead to an increase in customer loyalty (Jayaraman et al., 2012). Research suggests consumers are willing to pay a premium, up to $40 \%$ more, for products from horticultural industries that are produced using environmentally sound practices (Behe et al., 2013; Laroche et al., 2016).

Consumers who are typically willing to pay more for environmentally friendly products are female, married, and have at least one child living at home (Laroche et al., 2016). Additionally, consumers 36 to 50 years of age are the most likely to be proactively purchasing products from environmentally friendly companies (Patel et al., 2017). Incidentally, research found that younger consumers are more concerned about the environment but may lack the necessary income to purchase sustainable products at the same rate as middle-aged and older adults due to the associated higher costs (Panzone et al., 2016). Environmentally conscious consumers spent a total of $\$ 128.5$ billion on sustainable goods in 2018 and are projected to spend $\$ 150$ billion on sustainable goods by 2021 (Nielsen, 2018). This realization led businesses from all over the world to alter their supply chains to reduce waste (Jayaraman et al., 2012).

According to the U.S. Environmental Protection Agency (EPA), composting is one of several environmentally friendly ways to offset waste that would otherwise enter a landfill and is often easier to implement at a local level when decision-makers and the general public see the value of such a program (Bradley, 2014; EPA, 2019). The trend of environmental self-regulation, willingly imposing more stringent environmental policies than those required by the government, is progressing toward a time where environmentally friendly practices will be a competitive necessity for businesses to survive (Jayaraman et al., 2012).

In industrialized nations, as cities expand due to the migration of people from rural to urban areas, the problem of where to dispose of all the daily waste humans create, remains an issue. Most waste generated ends up in a landfill, a discrete area of excavated land in which garbage is buried (EPA, 2019). As of 2015, the most recent year for which data are available, 262.4 million tons of municipal solid waste was generated, of which 137.7 million tons were disposed of in landfills; an estimated 10.8 million tons of this waste is categorized as yard

\begin{tabular}{llll}
\hline $\begin{array}{l}\text { Units } \\
\begin{array}{l}\text { To convert U.S. to SI, } \\
\text { multiply by }\end{array}\end{array}$ & U.S. unit & SI unit & $\begin{array}{l}\text { To convert SI to U.S., } \\
\text { multiply by }\end{array}$ \\
\hline 0.4536 & $\mathrm{lb}$ & $\mathrm{kg}$ & 2.2046 \\
0.9072 & ton(s) & tonne $(\mathrm{s})$ & 1.1023
\end{tabular}

\footnotetext{
Horthathol December $202030(6)$
} 
trimmings, which would include grass, leaves, and brush (EPA, 2019). According to one study, total landfill capacity in the United States is forecasted to decrease by more than $15 \%$ over the next 5 years and by 2021 , only 15 years of landfill capacity will remain (Thompson, 2018).

Estimates of operational landfills in the United States range from 1700 to 2000 and make up the third largest source of methane emissions in the United States, emitting the equivalent of 107.7 million tonnes of carbon dioxide in the form of methane in a single year into the atmosphere (EPA, 2017). Greenhouse gases, such as carbon dioxide, methane, and nitrous oxide, trap some of the earth's outgoing heat, causing heat to be retained in the atmosphere (EPA, 2018). Trapped heat causes a radiative imbalance, the balance between energy received from the sun and emitted from the earth, thus altering climate and weather patterns at a global and regional level (EPA, 2018).

Offsite or community composting is one of the suggestions given by the EPA to offset the amount of waste entering landfills and waterways (EPA, 2019). Composting is also an innovative way to involve waste generators in their own waste treatment, raising community environmental awareness (Arrigoni et al., 2018). An additional consideration regarding floral shop waste includes the potential excessive leaching of pesticides (Singh et al., 2017) into land and waterways because floral products are produced with a host of chemicals.

During a personal interview with the manager of The University Florist, a full-service retail flower shop located on the campus of Mississippi State University, Mississippi State, MS, it was found that on average, 60 $\mathrm{lb}$ of fresh cut floral waste is disposed of weekly, an estimated $3120 \mathrm{lb} /$ year, from this single retail flower shop. It was also found that most retail florists in the industry dispose of their floral waste in municipal dumpsters in plastic garbage bags (T. Bowden, personal communication). There are an estimated 13,200 retail flower shop locations in the United States, comprising single- and multiple-location companies (Dun and Bradstreet, 2019). States with the highest employment levels of florists include
California, Texas, Florida, Missouri, and New York (U.S. Bureau of Labor Statistics, 2018).

In recent years there has been a push in the floral industry to become more sustainable and environmentally aware (Thursd, 2020). At the biennial Trend Summit, Conference, Symposium, and Workshop in which professionals within the floral industry meet to discuss the most current trend directions in floral design, the first statement on sustainability was crafted, which states, in part, a belief in the zero-waste hierarchy to rethink, redesign, reduce, and repurpose (Thursd, 2020). One method a company can use to differentiate itself from the rest and remain competitive is through branding. Branding has been shown to increase profit margins and help to stimulate demand in a saturated market (Collart et al., 2010). In recent years, there have been a number of brands established in the green industry as well as through state-sponsored programs (Collart et al., 2010). The main purpose of branding is to increase profits by raising awareness and increasing demand among consumers through promotion (Collart et al., 2010). Behe et al. (2013) concluded, "environmentally and socially responsible business differentiation strategies have become important components for the green industry's competitive landscape," after studying consumer preferences for local sustainable plant production characteristics, especially with the maturation of the industry.

The main purpose of this research was to investigate the perceptions of environmental health of retail flower shop owners and their willingness to recycle fresh cut floral waste produced at retail flower shops for use as compost and to determine whether there is a statistical correlation between environmental awareness and willingness to compost fresh cut flower waste.

\section{Materials and methods}

SAMPLE. Institutional review board exemption approval was granted for this research (IRB Protocol 19-122; Mar. 2019). A mailing list of retail florists was assembled by conducting a web-based search for retail florists in each of the 50 states. Using a "florist finder" website, a by-county search within each state was conducted to ensure all regions within a state were represented and not just those areas around large urban areas. The online survey was emailed to 1974 retail florists within all 50 states and Washington, DC, over a 4-month span (July-Oct. 2019). There are fluctuating numbers of florists in each state due to population differences within regions. Therefore, the number of florists contacted in each state also varied. However, efforts were made to contact as many florists within each state as possible. On average, 39 florists were contacted in each state. Florists from all 50 states were sent a standardized e-mail explaining the purpose of the study. Embedded in the e-mail was a hyperlink that redirected willing respondents to the survey. Survey responses were not linked to any identifiable respondent records, so responses would be anonymous. Each person on the mailing list was emailed only one time to avoid multiple responses by any individual.

Perceptions of environmental HEALTH AND WILLINGNESS TO COMPOST FLORAL WASTE QUANTITATIVE SURVEY. The survey instrument consisted of 28 questions in three sections. It was a modified version of a previously used instrument used to determine attitudes of environmental health (Wojtowicz, 1995). The first section included 15 five-point Likert-type (Likert, 1932) questions pertaining to respondents' attitudes toward environmental health and their willingness to separate and collaborate on composting waste produced at their flower shop. Answers included "strongly disagree," "disagree," "agree somewhat," "agree," and "strongly agree." Examples of questions included "My individual efforts within environmental protection each day can directly improve our environment," "More and tougher laws should be passed to change individual behavior related to environmental protection," and "Environmental problems are the result of the habits or behavior of everyone who lives in our society" (Wojtowicz, 1995). Overall, respondents' scores could range from 15 through 75. Higher scores indicated more concern toward environmental health and willingness to make changes to improve environmental health. The Cronbach's alpha reliability score for the environmental 
health section after modification was 0.80 .

The second section consisted of six questions asking respondents how they currently dispose of floral waste and the frequency at which they dispose of it. Examples of questions included "How many trash cans do you currently use inside your floral shop to dispose of floral waste?" "Do you currently recycle or compost your fresh cut flower waste produced at your retail flower shop?" and "Do you use plastic garbage bags in the trash cans in which you dispose of floral waste?"

The final section consisted of seven demographic questions asking respondents to provide their age, education level, annual household income, gender, and ethnicity. These were based on a reliable instrument used in a previous similar study (Short et al., 2017).

Data Analysis. Data from the survey were analyzed using descriptive and frequency statistics. Pearson's product-moment correlation tests were used to determine whether there were correlations between variables. Demographic comparisons were also made between groups using analysis of variance (ANOVA) tests.

\section{Results and discussion}

Survey RESPONSE. The survey was successfully completed by 300 respondents from 49 states and Washington, DC, within the United States who identified themselves as the owner or final decision-maker of the retail flower shop $(15.19 \%$ response rate, $100 \%$ completion rate). No florists from the state of Nebraska responded to the survey. Because the sample included only those who volunteered to take the survey instead of a randomly sampled population, the results are not necessarily generalizable beyond this study.

Of the retail florists who responded, $84(28.0 \%)$ were male and $216(72.0 \%)$ were female. Respondents tended to be middle aged or older adults with most respondents, 253 (84.3\%), being 40 years of age or older. Regarding ethnicity, the majority, 286 (95.3\%), of retail floral shop owners identified as "white or Caucasian." Respondents were asked the highest level of education they had achieved, 37 (12.3\%) indicated having achieved a "GED/ high school diploma," 93 (31.0\%) had taken "some college," 131 $(43.7 \%)$ had obtained a "college degree," 37 (12.3\%) indicated having a "postgraduate degree," and 2 $(0.7 \%)$ said they had a "trade school degree." These findings are consistent with previous demographic data collected by the U.S. Bureau of Labor and Statistics (2019), which found the most common owner of a retail flower shop to be middle aged (47.1 years of age), Caucasian $(88.7 \%)$, and female $(74.9 \%)$.

RETAIL FLORAL SHOP OWNERS' ATTITUDES TOWARD ENVIRONMENTAL HEALTH. Respondents were classified as having a low, medium, or high concern toward environmental health based on their responses to 15 Likerttype statements. Scores were recoded to equalize inversely, five negatively worded, scored items. Individuals with 35 or fewer points (indicating most responses were, on average, scored 1 or 2 points) were ranked as having "low concern." Individuals with 36 to 55 points (indicating most responses were, on average, scored 3 points) were "medium concern," and individuals with 56 or more points (indicating most responses were, on average, scored 4 or 5 points) were "high concern." Cut-off values were determined based on a similar past study (McFarland et al., 2008). Descriptive statistics determined the mean score for all respondents to be 57.41 , indicating most respondents as having a high concern for environmental health. Frequency statistics determined a majority of respondents, 190 (63.33\%), were ranked as having "high concern" for environmental health, 109 (36.33\%) were ranked as having "medium concern," and $1(0.33 \%)$ were ranked as having "low concern."

A Pearson's product-moment correlation compared the relationship between how respondents answered two questions pertaining to their willingness to compost flower waste and collaborate with others to do so and their classification as having "low," "medium," or "high" concern for environmental health. A moderate positive statistically significant relationship was found between the way in which respondents answered the questions "I would be willing to separate my fresh cut floral waste from other waste if it would be recycled through composting" $\left(R^{2}=0.565\right.$, $P=0.001)$ and "I would be willing to collaborate with local community gardens and Master Gardener programs to compost the fresh cut floral waste produced at my flower shop" $\left(R^{2}=0.533, P=0.001\right)$. This showed that the greater the retail florists' concern for environmental health, the more willing they were to compost their floral waste and collaborate with Master Gardeners and community garden programs. Pearson's product-moment correlation boundaries were based on guidelines set by Evans (1996), which were as follows: 0.00 to 0.19 is "very weak," 0.20 to 0.39 is "weak," 0.40 to 0.59 is " $m o d-$ erate," 0.60 to 0.79 is "strong," and 0.80 to 1.00 is "very strong."

COMPARISON BETWEEN RETAIL FLORIST ATTITUDES TOWARD THE ENVIRONMENT AND THEIR WILLINGNESS TO COMPOST FRESH CUT FLORAL WASTE. A Pearson's product-moment correlation analyzing the relationship between how respondents answered questions pertaining to their attitudes toward environmental health and their willingness to compost fresh cut floral waste produced at their retail flower shop was calculated. Moderate statistically significant relationships were found between retail florists' willingness to separate fresh cut floral waste and 11 of the environmental health statements. A moderate positive statistically significant relationship was found between the way in which respondents answered the questions "I would be willing to separate my fresh cut floral waste from other waste if it would be recycled through composting" and "My individual efforts within environmental protection each day can directly improve our environment" $\left(R^{2}=0.412, P=0.001\right)$ (Table 1$)$. Additionally, there was a weak statistically significant negative relationship found between florists' willingness to compost fresh cut floral waste and the environmental health statement "Solutions to environmental problems are created by society, not individuals like me" $\left[R^{2}=-0.113, P=0.050\right.$ (Table 1)]. This indicated that the greater concern individual florists had toward the environment, the more they felt they could be part of the solution to the larger problem.

A moderate positive statistically significant relationship was found between the way respondents answered 
Table 1. Pearson's product-moment correlation matrix indicating the relationship between 300 retail flower shop owners' attitudes toward environmental health, their willingness to compost fresh cut floral waste produced at their retail flower shops, and their willingness to collaborate on composting in the study of perceptions of environmental health, and their willingness to compost fresh cut floral waste by retail flower shop owners.

\begin{tabular}{|c|c|c|c|c|c|c|}
\hline \multirow[b]{2}{*}{ Attitude toward environmental health statements } & \multicolumn{3}{|c|}{$\begin{array}{l}\text { "I would be willing to separate } \\
\text { my fresh cut floral waste from } \\
\text { other waste if it would be } \\
\text { recycled through composting." }\end{array}$} & \multicolumn{3}{|c|}{$\begin{array}{l}\text { "I would be willing to } \\
\text { collaborate with local } \\
\text { community gardens and/or } \\
\text { Master Gardener programs to } \\
\text { compost the fresh cut floral waste } \\
\text { produced at my flower shop." }\end{array}$} \\
\hline & $\begin{array}{c}\text { Pearson } \\
\text { correlation }\end{array}$ & $P$ & $\mathbf{N}$ & $\begin{array}{c}\text { Pearson } \\
\text { correlation }\end{array}$ & $P$ & $\mathbf{N}$ \\
\hline $\begin{array}{l}\text { "More and tougher laws should be passed to change } \\
\text { individual behavior related to environmental protection." }\end{array}$ & 0.425 & $0.001^{*}$ & 300 & 0.400 & 0.001 * & 300 \\
\hline $\begin{array}{l}\text { "There is a direct link between environmental hazards and my } \\
\text { health." }\end{array}$ & 0.340 & $0.001^{*}$ & 300 & 0.314 & $0.001 *$ & 300 \\
\hline $\begin{array}{l}\text { "A personal concern for the environment is necessary for } \\
\text { improvements in the environment." }\end{array}$ & 0.330 & $0.001^{*}$ & 300 & 0.316 & 0.001 * & 300 \\
\hline $\begin{array}{l}\text { "It is too late for our efforts to save the environment to be } \\
\text { successful." }\end{array}$ & -0.109 & 0.060 & 300 & -0.119 & $0.039 *$ & 300 \\
\hline $\begin{array}{l}\text { "Environmental problems are the result of the habits or } \\
\text { behavior of everyone who lives in our society." }\end{array}$ & 0.323 & $0.001^{*}$ & 300 & 0.306 & 0.001 * & 300 \\
\hline $\begin{array}{l}\text { "The attitudes of my friends and family affect my } \\
\text { environmental protection behavior." }\end{array}$ & 0.128 & $0.027^{*}$ & 300 & 0.112 & 0.052 & 300 \\
\hline $\begin{array}{l}\text { "Environmental extremists (tree huggers) make me angry and } \\
\text { unwilling to make a commitment to protect the } \\
\text { environment." }\end{array}$ & -0.330 & $0.001^{*}$ & 300 & -0.282 & $0.001^{*}$ & 300 \\
\hline $\begin{array}{l}\text { "Solutions to environmental problems are created by society, } \\
\text { not individuals like me." }\end{array}$ & -0.113 & $0.050^{*}$ & 300 & -0.074 & 0.204 & 300 \\
\hline
\end{tabular}

*Statistically significant at the 0.05 level.

the questions "I would be willing to collaborate with local community gardens and/or Master Gardener programs to compost the fresh cut floral waste produced at my flower shop" and 10 of the 15 environmental health statements. The highest correlation was found between the willingness to collaborate statement and the environmental health statement "I am willing to work in environmental protection even if it takes more effort and sacrifice on my part" $\left[R^{2}=0.512, P=0.001\right.$ (Table 1)]. This indicated that retail florists who responded as having more concern toward the health of the environment were also more willing to compost their fresh cut floral waste and collaborate with others in the horticulture industry to compost their floral waste, and they were willing to put in more effort on their part to compost floral waste.

DEMOGRAPHIC DATA COMPARISON. Analysis of variance tests were used to determine whether there were differences in responses to environmental health questions based on the gender, age, education level, and ethnicity of respondents (Table 2). Significant differences were found in all four demographic groups. Post hoc least significant difference and frequency tests were used to determine where these significant differences occurred within each demographic category. Overall environmental health scores were calculated based on respondents' demographics (Table 3 ).

On the basis of gender, ANOVA tests found significant differences in the way respondents answered four of the environmental health questions (Table 2). Frequency tests compared the way males and females responded to the environmental health statements found to be significantly different in the ANOVA tests (Table 2). Females [98.1\% (212)] "agreed somewhat" or stronger that a personal concern for the environment was necessary for making improvements to the environment compared with males $[92.8 \%(78)]$. Females [97.2\% $(210)]$ were also more willing to compost their fresh cut floral waste compared with males [88.0\% (74)] and collaborate with community and Master Gardener programs. Combined, $79.0 \%$ (237) of males and females "agreed somewhat" or stronger that offering incentives/rewards would encourage them to compost. 


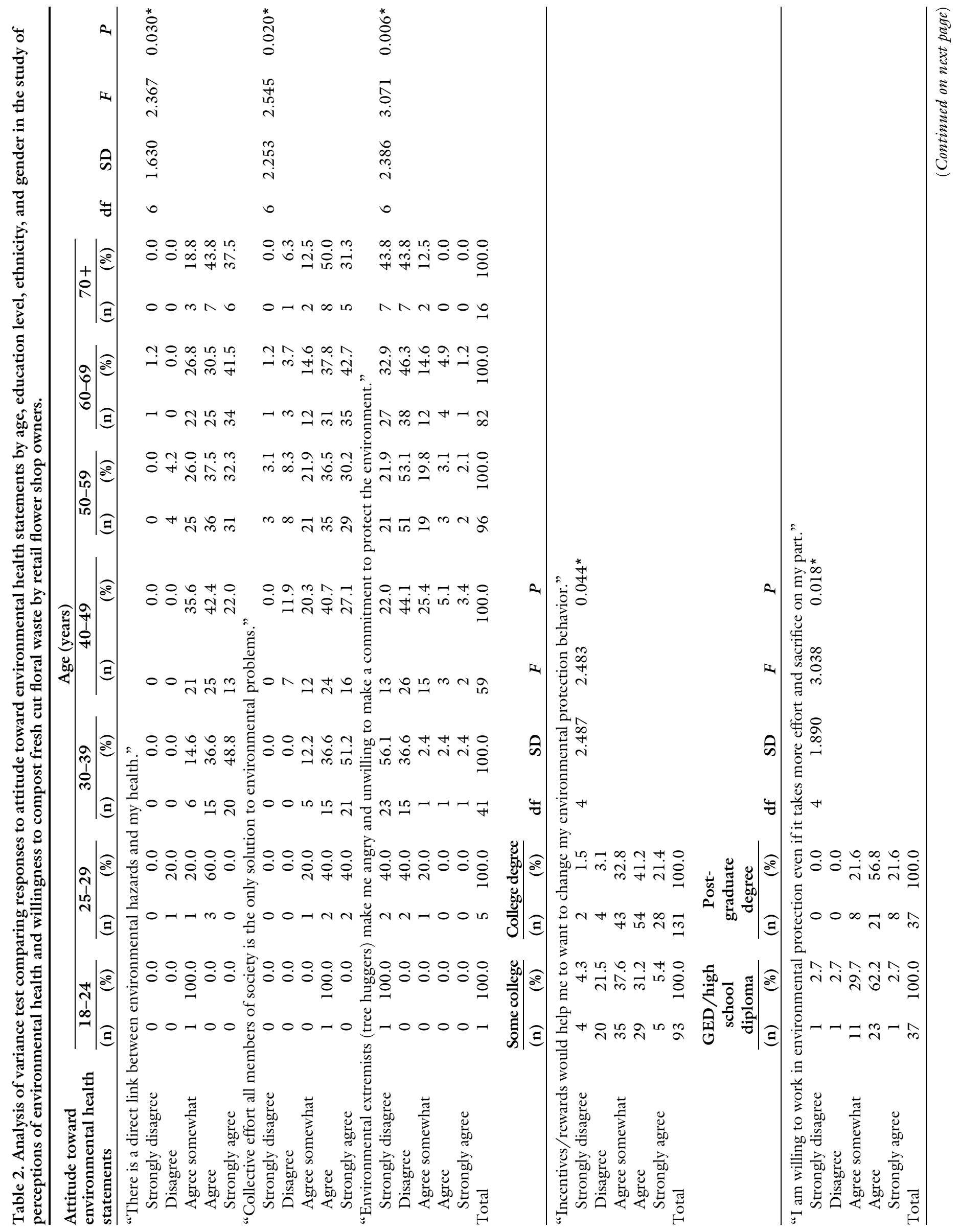

Hortlechnology · December 2020 30(6) 


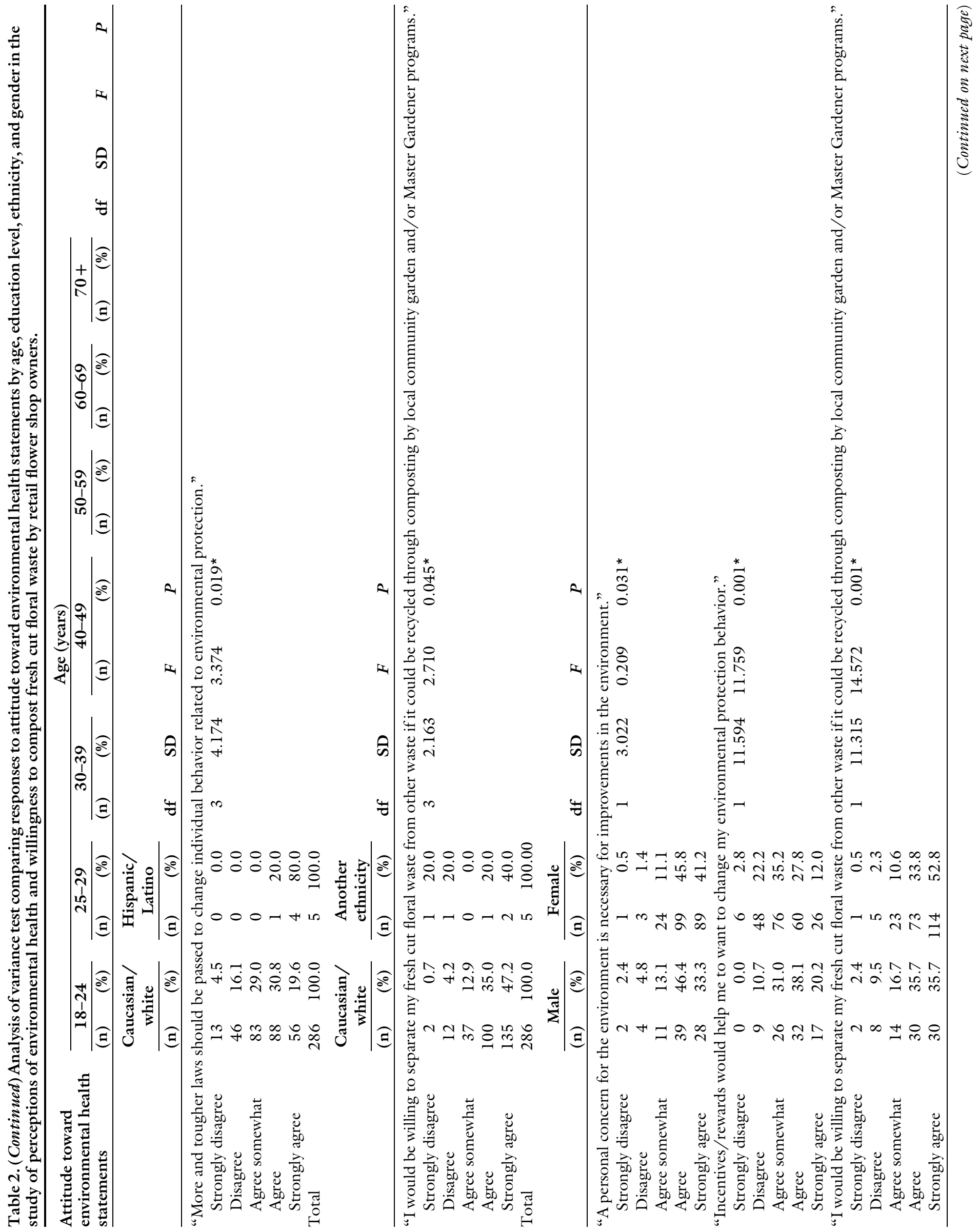




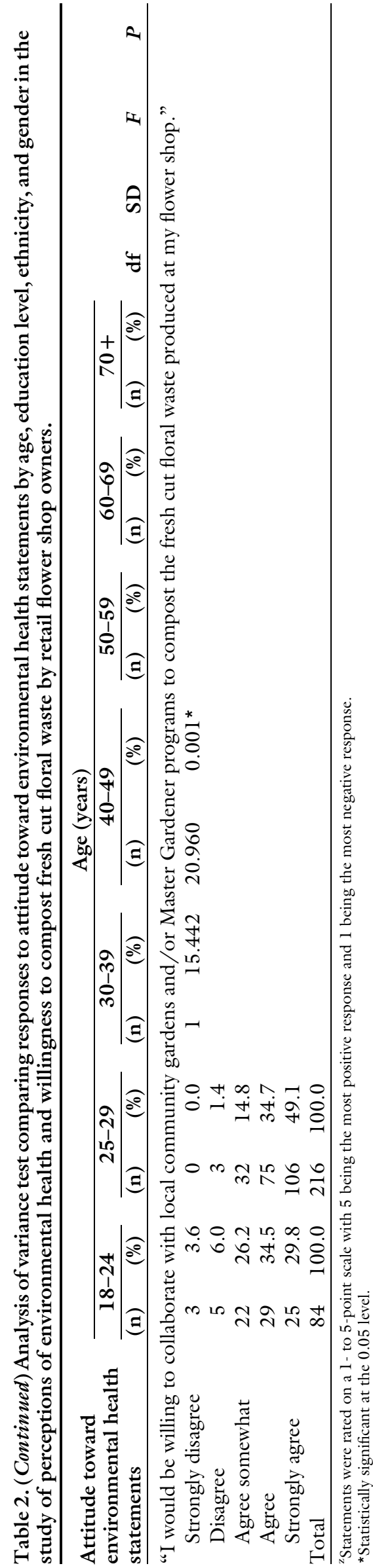

However, males [89.2\% (74)] indicated more of a desire to have incentive/rewards than did females [75.0\% (162)] (Table 2). Descriptive tests were used to compare overall scores of environmental health questions based on gender. Females on average scored a 58.23 , whereas males on average scored a 55.30. This indicated females had a greater concern for the health of the environment compared with males. This supported past research that found females to live more eco-friendly lifestyles, litter less, recycle more, and leave a smaller carbon footprint compared with men (Brough and Wilkie, 2017).

When comparing age groups, ANOVA tests found significant differences in three statements (Table 2 ). Frequency tests compared how different age groups responded to the environmental health statements in relation to each other (Table 2). The data showed respondents 49 years of age and younger $[99.3 \%$ (105)] "agreed somewhat" or stronger more often than respondents 50 years of age and older [97.4\% (189)] that there is a connection between their health and environmental hazards. Respondents 49 years of age and younger $[93.1 \%(99)]$ also viewed all members of society as the solution to environmental problems more so than respondents 50 years of age and older [91.3\% (168)]. Respondents 40 to 69 years of age $[25.7 \%(61)]$ had more anger toward environmental extremists compared with all other age groups combined $[9.5 \%(6)]$ (Table 2). Due to the relatively small sample size within certain age groups, the results could vary compared with a larger sample population. However, these findings support past research that found younger adults viewed environmental health as more personally important and expressed more of a willingness to engage in climate activism compared with older adults (Ballew et al., 2019).

Results of the ANOVA test found a statistically significant difference in the way participants responded to two questions based on their education level (Table 2). Post hoc tests were used to analyze where the differences existed in the ANOVA. For the incentive/rewards statement, statistically significant differences were found between respondents who had taken some college and respondents with a college degree. This indicated while most $[86.1 \%$ (194)] respondents from both groups "agreed somewhat" or stronger that incentives would be helpful to change environmental protection behavior, respondents with a college degree $[95.4 \%$ (125)] agreed more strongly with the statement compared with respondents with some college experience [74.1\% (69)] (Table 2). Statistically significant differences were found in the way respondents with a GED/high school diploma and postgraduate degree responded to the statement "I am willing to work in environmental protection even if it takes more effort and sacrifice on my part." This indicated respondents with a post graduate degree $[100.0 \%(37)]$ "agreed somewhat" or stronger with this statement when compared with respondents with a GED/high school diploma [94.5\% (35)] (Table 2). The results indicated respondents with higher education levels tended to have more of a concern for the health of the environment. Past research has found people with college degrees are $25 \%$ more likely, on average, to adopt environmentally friendly behaviors compared with those without college degrees. However, research showed any changes people make to help the environment need to fit in with their daily lifestyle (Economic and Social Research Council, 2011).

Significant differences were found in two statements based on ethnicity: "More and tougher laws should be passed to change individual behavior related to environmental protection" $[P=0.019$ (Table 2) $]$ and "I would be willing to separate my fresh cut floral waste from other waste if it could be recycled through composting by local community garden and/or Master Gardener programs" $[P=0.045$ (Table $2)$ ]. Post hoc tests showed a significant difference between the way Caucasian/ white and Hispanic/Latino respondents responded to the statement regarding tougher laws. Frequency tests indicated Hispanic/Latino florists [100.0\% (5)] "agreed somewhat" or stronger more often compared with Caucasians/white florists [79.3\% (227)] (Table 2). Post hoc tests also indicated a significant difference in the way Caucasian/white florists and florists who identified as 
Table 3. Overall environmental health statements scores based on age, education level, ethnicity, and gender in the study perceptions of environmental health and willingness to compost fresh cut floral waste by retail flower shop owners.

\begin{tabular}{lrc}
\hline Demographic & $\mathbf{n}$ & Overall environmental health score \\
\hline Age (years) & & \\
18-24 & 1 & 59.00 \\
$25-30$ & 4 & 53.60 \\
$30-39$ & 41 & 59.36 \\
$40-49$ & 59 & 56.23 \\
$50-59$ & 96 & 56.70 \\
60-69 & 82 & 58.08 \\
$70+$ & 16 & 58.68 \\
Education & & \\
Grade school only & 0 & 0 \\
Some high school & 0 & 0 \\
GED/high school diploma & 37 & 57.75 \\
Some college & 96 & 57.26 \\
College degree & 131 & 57.04 \\
Post graduate degree & 37 & 59.00 \\
Trade school degree & 2 & 53.00 \\
Ethnicity & & 57.31 \\
Caucasian/white & 286 & 63.60 \\
Hispanic/Latino & 5 & 0.75 \\
Black/African American & 0 & 54.20 \\
Asian American & 4 & 55.30 \\
American Indian & 0 & 5.23 \\
Another race & 5 & \\
Gender & & \\
Male & & \\
Female & & \\
\hline
\end{tabular}

another ethnicity not listed on the questionnaire responded to the statement "I would be willing to separate my fresh cut floral waste from other waste if it could be recycled through composting by local community garden and/or Master Gardener programs." Frequency tests indicated Caucasian/white respondents $[95.1 \%(272)]$ "agreed somewhat" or stronger when compared with florists that identified with another ethnicity [60.0\% (3)] not listed on the survey (Table 2 ). However, due to the relatively small sample sizes of those ethnicity groups that are not Caucasian/white, the results could vary in larger sample populations. Research has found that Caucasians are more likely to engage in environmental behaviors such as recycling, environmental reading, and joining conservation groups (Medina et al., 2019). However, the same research also found that compared with Caucasians, Hispanics/Latinos and African Americans have greater concern regarding environmental protection, toxic waste disposal, and the increasement of taxes for environmental regulations (Medina et al., 2019). Although the sample was small, this could explain why Hispanic/Latinos indicated a greater interest in having tougher environmental laws passed.

\section{Conclusions}

Of the 300 retail florists who took part in the survey a majority, $190(63.33 \%)$ were ranked as having "high concern" for environmental health. When analyzing florist perceptions of environmental health based on demographics, females indicated more of a willingness to compost floral waste and collaborate with others while doing so. Females also indicated a need for less incentives/ rewards to change their behaviors toward environmental protection.

Age played a role in how retail florists perceived a connection to their own health and the health of the environment. Younger florists, especially those 49 years of age and younger perceived their own health to be more directly related to the overall health of the environment. Compared with older florists, younger florists indicated that a collective effort was needed to find solutions to environmental problems and had less anger toward people thought of as environmental extremists compared with older florists.

Respondents with higher education levels indicated they would be more willing to put in additional time and effort to work on environmental protection but also showed an increased need for incentives and rewards to change their environmental protection behavior compared with respondents with lower levels of formal education. The fact that people are resistant to making changes in their lifestyles to be more eco-friendly might indicate reasons why retail florists with college degrees showed more of a desire for incentives/rewards to make pro-environmental health changes.

Overall, Caucasian/white florists indicated more of a willingness to separate their fresh cut flower waste than florists who listed their ethnicity as something other than the given choices. It was also found that Hispanic/Latino florists indicated more willingness to have tougher laws passed compared with Caucasians/ white florists.

A growing number of consumers, especially younger consumers, are starting to make purchase selections based on how "green" a company is (Nielsen, 2018). Additionally, research indicates that consumers are often willing to pay a premium for a product from an environmentally conscious business (Behe et al., 2013; Laroche et al., 2016). Little research has been conducted on best practices for disposing of cut floral waste created by retail flower shops or on how the retail florist might contribute to making the industry more environmentally sustainable overall. With environmentally conscious consumers taking more interest in how products they purchase are designed and sourced, the way in which a retail florist disposes of their fresh cut floral waste could be used as a form of promotion to set businesses apart from others in the industry. The process of composting fresh cut floral waste could be conducted by individual florists that have the space and knowledge to do so or through collaboration with local city governments, Master Gardner groups, community gardens, public school systems, and universities. Through the creation of industry- and state-sponsored 
brands/certifications, florists could brand and promote their business as more environmentally conscious by composting their floral waste, which in turn could stimulate sales and increase profit margins while having the added benefit of reducing the amount of waste entering landfills.

A majority of florists in the study indicated some degree of willingness to collaborate on composting fresh cut floral waste produced at their retail flower shop location. This offers the opportunity for further research into best practices for composting retail flower shop waste. Research should also be conducted on the types of incentives/rewards florists find most motivating to make a change to composting floral waste produced at their retail flower shop. Additionally, research could investigate the potential for associations within the floriculture and horticulture industry on creating "environmentally aware" certifications for retail florists willing to direct efforts in creating environmentally sustainable business models.

Limitations in the study included a small sample size, especially within some demographic groups, and the fact that respondents volunteered to take the survey instead of being randomly sampled. Because of these limitations, the results are not necessarily generalizable beyond this study. This study did not collect information on the region/state from which the respondent was answering within the survey. In future research, it is recommended that this information be collected and comparisons made to examine for regional differences and similarities in environmental health and willingness to compost fresh cut floral waste by retail flower shop owners.

\section{Literature cited}

Arrigoni, J.P., G. Paladino, L.A. Garibaldi, and F. Laos. 2018. Inside the small-scale composting of kitchen and garden wastes: Thermal performance and stratification effect in vertical compost bins. Waste Mgt. 76:284-293, doi: 10.1016/j.wasman. 2018.03.010.

Ballew, M., J. Marlon, S. Rosenthal, A. Gustafson, J. Kotcher, E. Maibach, and A. Leiserowitz. 2019. Do younger generations care more about global warming? 21 May 2020. <https://climatecommunication. yale.edu/publications/do-younger- generations-care-more-about-globalwarming/>.

Behe, B.K., B.L. Campbell, C.R. Hall, H. Khachatryan, J.H. Dennis, and C. Yue. 2013. Consumer preferences for local and sustainable plant production characteristics. HortScience 48:200-208, doi: 10.21273/HORTSCI.48.2.200.

Bradley, A.L. 2014. Organic materials management \& composting for rural, small, and tribal communities. 4 Nov. 2019. <https://nerc.org/documents/ Organics/Organics\%20Management\% 20 and\%20Composting\%20Guide.pdf $>$.

Brough, A.R. and J.E.B. Wilkie. 2017. Men resist green behavior as unmanly: A surprising reason for resistance to environmental goods and habits. 21 May 2020. <https://www.scientificamerican. com/article/men-resist-green-behavioras-unmanly $/>$.

Collart, A.J., M.A. Palma, and C.R. Hall. 2010. Branding awareness and willingness-to-pay associated with the Texas superstar and earth-kind brand in Texas. HortScience 45:1226-1231, doi: 10.21273/ HORTSCI.45.8.1226.

Dun and Bradstreet. 2019. Florists industry portfolio. 20 Oct. 2019. <http:// www. firstresearch.com/IndustryResearch/Florists.html>.

Economic and Social Research Council. 2011. When it comes to the environment, education affects our actions. 21 May 2020. <https://www.sciencedaily.com/ releases/2011/03/110321093843. htm $>$.

Evans, J.D. 1996. Straightforward statistics for the behavioral sciences. Brooks/ Cole, Pacific Grove, CA.

Jayaraman, V., R. Singh, and A. Anandnarayan. 2012. Impact of sustainable manufacturing practices on consumer perception and revenue growth: An emerging economy perspective. Intl. J. Prod. Res. 50:1395-1410, doi: 10.1080/ 00207543.2011 .571939 .

Laroche, M., J. Bergeron, and G. BarbaroForleo. 2016. Targeting consumers who are willing to pay more for environmentally friendly products. J. Consumer Mktg. 18:503-520, doi: 10.1108/ EUM0000000006155.

Lernoud, J. and H. Willer. 2017. The organic and fairtrade market 2015, p. 143-148. In: H. Willer and J. Lernoud (eds.). The world of organic agriculture. 18th ed. Res. Inst. Organic Agr., Frick, Switzerland.

Likert, R. 1932. A technique for the measurement of attitudes. Arch. Psychol. 22:140-155.
McFarland, A.L., T.M. Waliczek, and J.M. Zajicek. 2008. The relationship between student use of campus green spaces and perceptions of quality of life. HortTechnology 18:232-238.

Medina, V., A. DeRonda, N. Ross, D. Curtin, and F. Jia. 2019. Revisiting environmental belief and behavior among ethnic groups in the U.S. 21 May 2020. <https://www.ncbi.nlm.nih.gov/pmc/ articles/PMC6446830/>.

Nielsen. 2018. Was 2018 the year of the influential sustainable consumer. 11 Nov. 2019. <https://www.nielsen.com/us/ en/insights/article/2018/was-2018the-year-of-the-influential-sustainableconsumer $/>$.

Ouvrard, S., S.M. Jasimuddin, and A. Spiga. 2020. Does sustainability push to reshape business models? Evidence from the European wine industry. Sustainability 12:2561, doi: 103390/sul2062561.

Panzone, L., D. Hilton, L. Sale, and D. Cohen. 2016. Socio-demographic, implicit attitudes, explicit attitudes, and sustainable consumption in supermarket shopping. J. Econ. Psychol. 55:77-95, doi: 10.1016/j.joep.2016.02.004.

Patel, J., A. Modi, and J. Paul. 2017. Proenvironmental behavior and socio-demographic factors in an emerging market. Asian J. Bus. Ethics 6:189-214, doi: 10.1007/s13520-016-0071-5.

Raynolds, L.T. 2012. Fair trade flowers: Global certification, environmental sustainability, and labor standards. Rural Sociol. 77:493-519, https://doiorg/10. 1111/j.1549-0831.2012.00090.x.

Short, K., C.L. Etheredge, and T.M. Waliczek. 2017. Studying the market potential for specialty cultivars of sunflower cut flowers. HortTechnology 27:611-617.

Singh, P., A. Borthakur, R. Singh, S.H. Awasthi, D.B. Pal, P. Srivastava, D. Tiwary, and P.K. Mishra. 2017. Utilization of temple floral waste for extraction on valuable products: A close loop approach towards environmental sustainability and waste management. J. Pollution 3:39-54.

Thompson, J. 2018. Time is running out: The U.S. landfill capacity crisis. 3 Nov. 2019. <https://www.wasteinfo.com/ news/wbj20180514A.htm>.

Thursd. 2020. Trend summit 2020 report. 30 Sept. 2020. <https://www. thursd.com/articles/trend-summit2020 report $/$ ? fbclid $=$ IwAR 25 q 20 Iryp0pt8DjwI4yCzNAvPWutGidvAzh6 JAUMmvse4FOY157d1PA>. 
Toumi, K., C. Vleminckx, J. Van Loco, and B. Schiffers. 2016. Pesticide residues on three cut flower species and potential exposure of florists in Belgium. Intl. J. Environ. Res. Public Health 13:943, doi: 103390/ijerph13100943.

U.S. Bureau of Labor Statistics. 2018. Occupational employment and wages floral designers. 20 Oct. 2019. <https://www. bls.gov/oes/current/oes271023.htm>.

U.S. Bureau of Labor Statistics. 2019. Labor force statistics from the current population survey. 22 May 2020. <https://www.bls.gov/cps/cpsaat 18 . htm>.

U.S. Environmental Protection Agency. 2017. Inventory of U.S. greenhouse gas emissions and sinks. 28 Oct. 2019. <https:// www.epa.gov/sites/production/files/ 2019-04/documents/us-ghg-inventory2019-main-text.pdf>.

U.S. Environmental Protection Agency. 2018. Greenhouse gases: What are the trends in greenhouse gas emissions and concentrations and their impacts on human health and the environment. 1 Nov. 2019. <https://www.epa.gov/reportenvironment/greenhouse-gases $>$.
U.S. Environmental Protection Agency. 2019. National overview: Facts and figures on materials, wastes, and recycling. 15 Sept. 2019. <https://www.epa.gov/ facts-and-figures-about-materials-wasteand-recycling/national-overview-factsand-figures-materials $>$.

Wojtowicz, G.G. 1995. Health and environmental protection: A survey of student attitudes. 3 Feb. 2019. <https://eric.ed. gov $/$ ? id $=$ ED386447>. 